\title{
Temporal dynamics of antibiotics in wastewater treatment plant influent
}

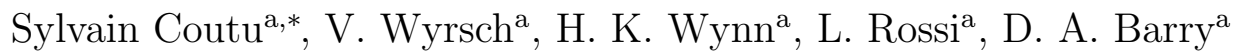 \\ ${ }^{a}$ Laboratoire de technologie écologique, Institut d'ingénierie de l'environnement, Faculté \\ de l'environnement naturel, architectural et construit (ENAC), Station 2, Ecole \\ Polytechnique Fédérale de Lausanne (EPFL), 1015 Lausanne, Switzerland
}

\begin{abstract}
A yearlong field experimental campaign was conducted to reveal time scales over which antibiotic fluxes vary in the influent of a wastewater treatment plant (WTP). In particular, sampling was carried out to ascertain the amplitudes of monthly, daily and hourly fluctuations of several antibiotics. A total of 180 samples was collected at the entrance of a WTP in Lausanne, Switzerland. Sample concentrations were multiplied by flow rate to obtain monthly, daily and hourly mass fluxes of six antibiotics (trimethoprim, norfloxacin, ciprofloxacin, ofloxacin, clindamycin and metronidazole). Seasonality in mass fluxes was observed for all substances, with maximum values in winter being up to an order of magnitude higher than in summer. The hourly measurements of the mass flux of antibiotics were found to have a period of $12 \mathrm{~h}$. This was due to peaks in toilet use in the morning and early evening. In particular, the morning peak in flushing coincided with high concentrations (and hence high mass fluxes) due to overnight accumulation of substances
\end{abstract}

\footnotetext{
*corresponding author. Tel: +41 (0)21-693-8024.

Email address: sylvain.coutu@epfl.ch (Sylvain Coutu)
} 
in urine. However, little variation was observed in the average daily flux. Consequently, fluctuations in mass fluxes of antibiotics were mainly evident at the monthly and hourly time scales, with little variation on the day-week time scale. These results can aid in optimizing removal strategies and future sampling campaigns focused on antibiotics in wastewater.

Keywords: Pharmaceuticals, Water quality, Mass loading, Sampling, Time scale, Fluctuation 


\section{Introduction}

Although the quality of natural waters has been investigated extensively, continuing efforts are directed to understand better the complex dynamics of wastewater discharges to the environment. The most studied and best treated wastewater pollutants are organic materials and nutrients. On the other hand, the origin and fate of emerging pollutants, also referred as micropollutants, are still insufficiently understood (Ternes and Joss, 2006; Verlicchi et al., 2012). There is a plethora of micropollutants, each of which potentially displays different behavior in the environment (Kleywegt et al., 2011; Rimkus, 1999). Here, we examine the dynamics of antibiotic mass fluxes in a wastewater treatment plant (WTP) influent.

Antibiotics have been measured in WTP influents worldwide (Hirsch et al., 1999; Kümmerer, 2009; Tamtam et al., 2008). They are suspected to present an environmental risk, e.g., fostering bacterial resistance (Czekalski et al., 2010; Servais and Passerat, 2009). For this reason, antibiotics in urban systems and discharges have been subject to increased investigation in the last decade (Neu, 1992; Pruden et al., 2006; Verlicchi et al., 2012). Several studies have reported evidence of seasonal fluctuations in concentrations of various antibiotics in WTPs and in natural waters (Conley et al., 2008; Göbel et al., 2005; Lissemore et al., 2006; Santos et al., 2009). The changing wastewater characteristics and imposition of stricter wastewater discharge regulations have led to a greater emphasis on WTP inlet fluxes (Tchobanoglous et al., 2003). Process modeling of activated sludge dynamics is becoming increasingly important, as is the characterization of the dynamics of WTP influent (Hulsbeek et al., 2002). The temporal dynamics of 
ammonia and dissolved organic carbon for instance have already been well described (Tchobanoglous et al., 2003). However, there are few studies that assess the time variability of antibiotics. In Table 1, we summarize existing studies reporting antibiotic dynamics at WTP inlets.

In a paper aiming to assess the removal of pharmaceuticals and fragrances in a WTP, Joss et al. (2005) observed some fluctuations in antibiotic concentrations at the WTP inlet, but the sampling methodology (8-h composite samples, Table 1) was insufficient to determine details of the influent dynamics. In another study, Plósz et al. (2010) measured the diurnal variation of hormones and antibiotics in activated sludge wastewater, as part of their overall goal of linking posology and observed concentrations. However, similarly to Joss et al. (2005), Plósz et al. (2010) used 8-h composite samples taken after the primary clarifier to assess the temporal variability (Table 1). That is, in both studies, the authors collected three 8-h composite samples per day. Plósz et al. (2010) had a total of nine samples (3 sampling days) whereas Joss et al. (2005) sampled for $1 \mathrm{~d}$ giving a total of three samples. In both cases, the sampling frequency (3 per day) and the total number of samples are insufficient to identify diurnal variability. Gerrity et al. (2011) and Teerlink et al. (2012) identified a diurnal pattern consisting of two mass flux peaks in WTP influent, one in the morning followed by a lower peak during the night (Table 1). Salgado et al. (2011) investigated day-to-day variation of chemicals and measured a load of pharmaceuticals that surprisingly varied by an order of magnitude from one day to the next. These authors concluded that the dynamics of pharmaceuticals needed further investigation to understand the variability in more detail. 


\section{Table 1 near here}

The studies listed in Table 1 generally observed a peak in morning concentrations. This observation is not surprising as antibiotics and other substances ingested during the evening accumulate in urine during sleep (Noh et al., 2011; Pandi-Permural and Cardinali, 2007). However, all the cited studies were not designed to examine the temporal variability of antibiotics in WTP influent in a systematic way (i.e., over different time scales). In this work, our objective was to uncover time scales in mass fluxes of representative antibiotics in WTP influent. To this end, we performed a yearlong on-site experimental campaign with sufficient sampling to capture hourly to seasonal fluctuations. Besides its scientific interest, the study has the potential to help in the optimization of micropollutant removal in WTPs. More particularly, the results will underpin the design of future sampling campaigns focusing on antibiotics, as well as the interpretation of data sets, e.g., short-term sampling campaigns.

\section{Materials and Methods}

\subsection{Sample collection}

A yearlong study was conducted at the Vidy WTP, in Lausanne, Switzerland. The WTP collects wastewater for approximately 220,000 inhabitants, and several hospitals. The latter contribute about $\sim 1 \%$ of the total wastewater volume of reaching the WTP. The automatic sampler was installed at the entrance of the WTP, upstream of the primary settling tank, in order to capture the dynamics of the mass flux of incoming antibiotics. Starting in 
March 2011, 12 (i.e., once each month) weeklong sampling campaigns were conducted. These campaigns consisted of seven daily-composite samples, collected for the seven consecutive days (84 samples collected in total). A daily-composite sample was obtained by mixing (flow proportionally) 24 individual (hourly) 200-ml samples collected with an automatic sampling device (6712FR Teledyne ISCO). Collected samples were stored on-site in plastic bottles inside a refrigerated sampling device at a temperature below $4^{\circ} \mathrm{C}$ before collection for laboratory analysis. Samples were analyzed or frozen at $-20^{\circ} \mathrm{C}$ within $24 \mathrm{~h}$ after collection.

In addition to the yearlong campaign, four 24-h campaigns were conducted to evaluate the dynamics at the hourly scale. The four campaigns were conducted during four different months: December, May, September and November. Each 24-h campaign provided 24 samples (96 in total), one per hour, starting at 07:00. Each hourly sample was the aggregation of four 200-ml wastewater samples collected every $15 \mathrm{~min}$.

The different field campaigns are summarized in Table 2. All samples were collected at the same location using the same sampler. Water samples were analyzed using online SPE UPLC-MS/MS, and concentrations were obtained for six antibiotics - trimethoprim, norfloxacin, ciprofloxacin, ofloxacin, clindamycin, metronidazole - for a total of 1080 analyses. These six antibiotics were classified has priority substances based on physico-chemical characteristics in a previous study (Coutu et al., 2012) and because they were measured in Vidy Bay, where the WTP discharges its effluent (Bonvin et al., 2011).

The sampling program allows comparison of mass flux fluctuations monthto-month, day-to-day and hour-to-hour, thereby providing information on the 
time scales that control antibiotic fluxes in wastewater.

\section{Table 2 near here}

\subsection{Flow measurements}

An ultrasonic sensor was installed next to the automatic sampler to record water levels at 5-min intervals. The water level was later converted into flow by use of the appropriate calibration ${ }^{1}$. All water flow data can be found in the Supplementary data.

\subsection{Sample treatment and chemical analysis}

As a first step samples were acidified to $\mathrm{pH}$ 2-2.5 with hydrochloric acid (concentrated 25\%). Then, samples were filtered, first, through 2.7- $\mu \mathrm{m}$ glass fiber pre-filters (type GF/D, Whatman). The pre-filtered samples were filtered again through $0.45-\mu \mathrm{m}$ membrane filters (type ME 25, mixed cellulose ester, Whatman). Samples were stored at $-20^{\circ} \mathrm{C}$ until analysis.

The analytical method involved online solid-phase extraction (SPE) and Ultra Performance Liquid Chromatography coupled with tandem mass spectrometer (Xevo UPLC-MS/MS, Waters). Frozen samples were thawed to room temperature prior to analysis. Then, $8 \mathrm{~mL}$ of each sample was filtered through $0.2-\mu \mathrm{m}$ syringe filters (type GMF, BGB-analytik) directly into the injection vials. A mixture of deuterated antibiotic surrogates was added with a gas-tight syringe into all injection vials (samples as well as standards). Targeted compounds were first extracted in the online SPE system, which

\footnotetext{
${ }^{1}$ http://www.isco.com, site last accessed in June 2012
} 
consisted of a $2.1 \times 20 \mathrm{~mm}$ SPE column (type Oasis HLB $25 \mu \mathrm{m}$, Waters). Extracted compounds were separated in a $2.1 \times 50 \mathrm{~mm}$ chromatographic analytical column (type Acquity UPLC BEH C18 $1.7 \mu \mathrm{m}$, Waters) with an organic mobile phase in gradient mode. All the targeted compounds were identified and quantified using tandem mass spectrometry according to their masses of precursor and product ions as well as their mass-to-charge ratios. More information on mobile phases and HPLC gradient used can be found in the supplementary materials.

The analytical limit of quantification (LOQ) was defined as the concentration of the lowest standard with a signal-to-noise ratio greater than 10 (Bonvin et al., 2011). The antibiotic concentration in the samples was calculated based on calibration curves using seven calibration points closest to the sample concentration. Correlation coefficients for the calibration curves were typically 0.99 at least. In the calculation of sample concentration, recovery rates of deuterated surrogates and exact sample mass weighed during sample preparation were taken into account for each associated antibiotic compound. Details of the precision of the method are summarized in Table 3.

\subsection{Data analysis}

We discuss mass fluxes of antibiotics rather than concentrations, since dilution occurs during rainy periods. Mass fluxes, or load, to the WTP is useful when different sites are compared (Johnson, 2010). Hereafter, we use the term "measured mass flux" to indicate the mass flux obtained by multiplying, for each sample, the measured flow and measured concentration.

Statistical techniques were used to assess potential temporal characteristics in mass flux fluctuations and the variability at different time scales 
(month, day, hour: $\mathrm{m}, \mathrm{d}, \mathrm{h}$ ) in the mass flux of antibiotics at the WTP inlet.

Calculations were carried out using Matlab². Standard statistical tests were performed (mean, median and different percentiles of the measured mass fluxes). In addition, the periodogram of the 96 hourly values was extracted to identify possible periodicity in the hourly dynamics. This was done by windowing the data using the technique of Welch (1967), after which the periodogram was computed using the fast Fourier transform.

\section{Results and Discussion}

\subsection{Seasonality of mass flux}

Mass fluxes measured monthly at the WTP inlet are compared. Seven consecutive daily samples were aggregated flow proportionally to form a monthly sample (Table 2). The median mass flux obtained is presented for each month and all substances in Figure 1. Minimum monthly mass fluxes are generally found during the period running from June to September. Mass fluxes measured in December and January have systematically higher values except for ciprofloxacin. High values are also observed in March for ciprofloxacin, ofloxacin and clindamycin. Note that an error in the experimental procedure meant that unfortunately we could not retrieve mass fluxes for the month of February.

In comparing the different time series of mass fluxes, data for a given time scale were normalized by the appropriate mean calculated for the considered data. Thus, hourly, weekly and monthly data were normalized by daily,

\footnotetext{
${ }^{2}$ Matlab 2009b, The Mathworks, Natick, Massachusetts, USA
} 
monthly and annual means, respectively. This allows comparison of variations in data sets with different means. For example, the monthly mass flux normalized by the annual mean is helpful to evaluate the seasonality of the different antibiotics, as well as the range of the month-to-month fluctuations. This relative fluctuation is presented in Figure 3a for the six antibiotics. The normalized monthly mass fluxes range between a quarter and double of the mean annual mass flux measured at the WTP inlet. Obvious seasonality is observed in the mass fluxes of ciprofloxacin, ofloxacin and clindamycin, with winter values being up to eight times greater than corresponding summer values. Trimethoprim, on the other hand, shows less variability in the monthly mass flux over the year, although a higher mass flux is still observed in January and December. The behavior of norfloxacin and metronidazole is somewhat peculiar; values of monthly mass fluxes are located broadly between a quarter and half of the mean, with a sudden rise in December and January. For all substances we observe that the highest mass flux is measured during the (winter) months of December and January.

The boxplot widths appear to be significant for some substances in Figure 1 (e.g., norfloxacin in January). This indicates that successive daily mass fluxes within a week were not constant, which should be the case for antibiotics (see §.3.3). This variability reflects the random nature of the inputs into the sewer system, as well as uncertainty in the measurements, which in the case of UPLC/MS-MS can be reasonably considered to range up to $20 \%$ (Bonvin et al., 2011).

\section{Figure 1 near here}


The clear seasonality in the observed mass flux of ciprofloxacin (Figure 1) can be explained by considering its therapeutic use. Ciprofloxacin is mainly prescribed to treat seasonal diseases like airway infections (i.e., bronchitis and pneumonia) and infections affecting the throat, nose and ears (pharyngitis, sinusitis, earache). The mass flux of norfloxacin is also affected by seasonality. It is also used to treat similar seasonal pathologies, albeit to a lesser extent than ciprofloxacin. In contrast, trimethoprim displays reduced seasonality in mass fluxes, corresponding to its use for non-seasonal diseases, typically urinary-genital tract infections. However, the connection between seasonality in prescriptions to that in mass flux is not systematic. Indeed, ofloxacin displays seasonality in mass flux dynamics, yet it is used to treat non-seasonal pathologies like skin or urinary-genital tract infections. It is thus difficult to explain seasonality (or lack thereof) in mass fluxes of specific compounds. Possibly, seasonal temperature changes are sufficient to influence degradation of some compounds while they are transported in the sewer system.

\subsection{Periodicity in hourly mass flux}

The four 24-h campaigns described in Table 2 were used to evaluate periodicity in the mass flux of antibiotics reaching the WTP during dry weather. For this, the measured hourly mass flux was first normalized to the mean for that day (Figure 3c). After normalization, data from the four 24-h campaigns were combined sequentially into a series of 96 experimental values. The periodogram for ciprofloxacin is shown in Figure 2. Periodograms for the five other antibiotics considered in this study can be found in the Supplementary data. 


\section{Figure 2 near here}

For all substances considered, two noticeable peaks appear in the computed periodogram, which indicates that the mass flux of antibiotics has a 12-h period. According to Figure 3c, the first peak occurs between 07:00 and 09:00. The magnitude of this morning peak is up to double that of the average daily flux reaching the WTP. It corresponds to the peak in toilet flushes observed by Friedler et al. (1996) and Rauch et al. (2003). The second peak occurs $12 \mathrm{~h}$ later, between 17:00 and 21:00. This peak is less pronounced than the morning peak, and occurs over a broader period. Its maximum is around 1.2 times the daily mean, except for metronidazole.

Consistent with previous observations, the fluctuations in the mass flux of antibiotics are greater than those of the flow rate (Figure 3c). Plósz et al. (2010) explained that the high peak in pharmaceutical load at the WTP inlet is due to posology. Antibiotics are typically administrated every 8 or 12 $\mathrm{h}$, with one ingestion occurring in late evening. During sleep, the antibiotic accumulates in urine and is released in the first toilet flush of the morning. Concentrations are thus relatively high, leading to the observed difference in fluctuations. A second peak in the mass flux, lower than the first, occurs approximately $12 \mathrm{~h}$ later (Figure 2 and 3c). This second peak was not observed by Plósz et al. (2010) as they used 8-h composite samples. The reduction in the magnitude of this peak results again from posology. Indeed, the posology of antibiotics is calculated so that they are metabolized at a constant rate. Due to more frequent toilet use during daytime, the concentration in the urine is, ideally, constant. Thus, the second peak observed is due to the corresponding increase in wastewater volume. For this reason the increase in 
mass flux of antibiotics and flow rate are in the same range (Figure 3c).

\subsection{Dominant time scale}

Mean normalized mass fluxes were used to compare the temporal dynamics of antibiotics at different time scales. The results are summarized in Figure 3. We observe that whereas monthly and hourly mean mass fluxes fluctuate between 0.25 and 2 times the corresponding mean (the annual mean and daily mean, respectively), very little fluctuation is observed at the daily scale (Figure 3b). All daily measured mass fluxes remain located between $\pm 20 \%$ of the weekly average, the only exception being metronidazole. A day-to-day variability in the usage of this last substance could be responsible for the observed variability at the WTP entrance (between 2.2 and 0.3 times the mean daily load flux, see Figure 3b). Indeed, some pathologies are treated by a single high dose of this compound (e.g., bacterial vaginosis, $2 \mathrm{~g}$ of metronidazole) (CDC, 2002). Depending on the number of people treated, these "single pulses" may explain the observed variability at this time scale. More medical data on the occurrence of these kind of diseases would help to characterize this behavior.

Figure 3 near here

\section{Figure 4 near here}

The dominance of variability in antibiotic mass fluxes at the monthly and hourly time scales over that at the daily time scale is illustrated in Figure 4. The variability of the daily mass flux (during the week) is systematically 
lower than that of the monthly mass flux considered over the year, or hourly mass flux over a day. Depending on the month or the hour of the sampling, the range of mass fluxes varies by up to an order of magnitude. This is due to two factors. First, antibiotic consumption is seasonal, thus so are the corresponding mass fluxes at the WTP entrance (Vernaz et al., 2008). Second, on the hourly time scale (during a given day), mass flux variability can be (partially) explained by toilet use frequency and the posology of the different antibiotics. These variations highlight the importance of the design of sampling campaigns for antibiotics in the environment Ort et al. (2010).

\subsection{Comparison with existing studies}

Comparisons of these results with existing studies is not straightforward as different analytical methods have been employed. In addition, there is variability in use of antibiotics and water between regions (Filippini et al., 2006).

Santos et al. (2009) conducted a 1-y field campaign at a WTP entrance to assess the dynamics of some micropollutants (not antibiotics). No clear pattern in the dynamics of the substances considered could be identified except for ibuprofen, where the authors suspected some seasonality. However, ibuprofen is an anti-inflammatory drug and seasonality in its use seems unlikely, especially when contrasted with antibiotics used to treat seasonal diseases such as airway infections (i.e., bronchitis and pneumonia) and infections affecting the throat, nose and ears (pharyngitis, sinusitis, earache). For the Lausanne WTP, ciprofloxacin shows the clearest seasonality, with the mass flux in winter being up to 4 times greater than that measured during summer. 
Göbel et al. (2005) assessed the seasonality of different antibiotics by comparing three weekly campaigns conducted in March, September, November and February (see Table 1) in Eastern Switzerland. Loads observed at the WTP inlet were generally higher in February and March than in September and November. This was explained by higher sales during these periods (sales data not provided) and, as mentioned above, by the seasonal use of these substances determined by the treated pathologies. Unfortunately, the number of samples collected was insufficient to determine a clear pattern in seasonal fluctuations of loads.

Salgado et al. (2011) assessed diurnal variability of several pharmaceuticals (and other chemicals) in wastewater influent. They sampled wastewater at a WTP inlet during two consecutive days (Monday-Tuesday), two weeks in a row. Ciprofloxacin was measured on the two Tuesdays. A factor of two in mass load was observed, which was difficult to explain given that the sampling methodology and weather conditions were consistent for the two sampling days. By comparison, our results have clearer underpinnings, due to the nested temporal sampling employed. For antibiotics, where the patient follows a prescribed posology, the consumption over the whole WTP basin would vary little from one day to the next. Thus, the daily mass flux should remain within the same order of magnitude. Consistent with this reasoning are the findings of Gerrity et al. (2011) and Huerta-Fontela et al. (2008), who found that compounds not subject to any posology (e.g., illicit products) do not follow this behavior.

The diurnal variability of pharmaceuticals was recently the subject of a study conducted at a WTP inlet in Norway. Plósz et al. (2010) observed a 
mass load up to three times greater in the morning than during the night for ciprofloxacin and trimethoprim. A similar pattern was observed in other studies assessing the temporal dynamics of pharmaceuticals (Göbel et al., 2005; Joss et al., 2005). A second peak observed by Teerlink et al. (2012) and Gerrity et al. (2011) in the late afternoon was simply explained by a corresponding rise in flow rate at WTP inlet. However, it would be beneficial to combine knowledge of posology, pharmacokinetics and toilet use frequency to obtain more insights on the hourly fluctuations of these substances at the WTP inlet. A modeling study in that direction is currently underway in our group.

\section{Conclusion}

We have assessed the dominant time scale in the mass flux variability of several antibiotics in sewage water reaching the Vidy WTP. Mass fluxes were observed to be higher in winter than in summer. This is particularly the case for ciprofloxacin, with the winter mass flux being up to 3-4 times that in summer. These data are consistent with the hypothesis that the measurements reflect the seasonal consumption of antibiotics, driven by associated seasonality in pathologies. However, further investigation is necessary to establish a correlation between consumption and measured load to confirm this hypothesis.

Little fluctuation was observed on a day-to-day basis. This indicates that, at the scale of the WTP catchment area, daily consumption of antibiotics varies only slowly. Metronidazole was found to behave differently, however, for reasons that are as yet unknown. 
Diurnal fluctuations in the mass flux of antibiotics show a similar trend for the six compounds investigated. Similarly to previous studies, a morning peak in mass flux was observed, which was not surprising as antibiotics accumulate overnight in the human body before being excreted in the morning. Another peak was generally observed $12 \mathrm{~h}$ later. Even though it is plausible that toilet use could explain this second peak, more knowledge on the pharmacokinetics of these antibiotics seems necessary to characterize more fully this mass flux increase.

Several conclusions on sampling design of antibiotics in wastewater can be drawn out of the results of this study. First, the day of the week selected for sampling has no influence on the load measured. Second, the seasonal consumption of the substance should be investigated when possible, as sizeable fluctuations of mass flux of antibiotics can be observed at the WTP inlet. Third, at least an hourly sampling frequency and analysis are needed when the objective of the study is to assess the intra-day dynamics of antibiotics, in order to capture the morning and late afternoon mass flux peaks.

More generally, posology, pharmacokinetics and toilet flush frequency control the mass flux of antibiotics in sewage water. These parameters should be accounted for when modeling the mass flux or concentrations in WTPs. The dataset presented here will aid such modeling efforts in the future.

\section{Supplementary data}

Supporting information is provided in the three files:

- A1 (A1_flow.xlsx): A spreadsheet (Excel) file containing all flow values measured during the different experimental campaigns; 
- A2 (A2_concentrations.xlsx): A spreadsheet (Excel) file containing all concentrations measured during the different experimental campaigns for each substance;

- A3 (A3_periodo_all): A PDF file with six figures representing the periodograms computed for the six antibiotics (cf. Figure 2);

- A4 (A4_GradientMode.docx): A word file with additional technical notes on the experimental procedure.

\section{Acknowledgment}

This yearlong field experimental campaign benefitted from contributions from several individuals. We would like to thank Emilie Grand, Jonas Margot, Yves Bonnefin and Lisa Hansberger. We acknowledge also the operators of the Vidy WTP for facilitating installation of our sampling devices and access to the WTP. We would also like to thank the reviewers for the care they took in reviewing this manuscript. Their contribution significantly helped in making the manuscript more comprehensive. 


\section{References}

Bonvin F, Rutler R, Chèvre N, Halder J, Kohn T. Spatial and temporal presence of a wastewater-derived micropollutant plume in Lake Geneva. Environmental Science \& Technology 2011;45(11):4702-9.

CDC . Sexually Transmitted Diseases Guidelines. Technical Report; Centers for Disease Control, MMWR; 51/RR6:43; 2002.

Conley JM, Symes SJ, Schorr MS, Richards SM. Spatial and temporal analysis of pharmaceutical concentrations in the upper Tennessee River basin. Chemosphere 2008;73(8):1178-87.

Coutu S, Rossi L, Barry DA, Chèvre N. Methodology to account for uncertainties and tradeoffs in pharmaceutical. Journal of Environmental Management 2012;98(8):183-90.

Czekalski N, Berthold T, Caucci S, Egli A, Buergmann H. Increased levels of multiresistant bacteria and resistance genes after wastewater treatment and their dissemination into Lake Geneva, Switzerland. Frontiers in Microbiology 2010;3:20-37.

Filippini M, Masiero G, Moschetti K. Socioeconomic determinants of regional differences in outpatient antibiotic consumption: Evidence from Switzerland. Health Policy 2006;78(1):77-92.

Friedler E, Butler D, Brown DM. Domestic WC usage patterns. Building and Environment 1996;31(4):385-92. 
Gerrity D, Trenholm R, Snyder, S.A . Temporal variability of pharmaceuticals and illicit drugs in wastewater and the effects of a major sporting event. Water Research 2011;45:5399-411.

Göbel A, Thomsen A, McArdell CS, Joss A, Giger W. Occurrence and sorption behavior of sulfonamides, macrolides, and trimethoprim in activated sludge treatment. Environmental Science \& Technology 2005;39(11):39819.

Hirsch R, Ternes TA, Haberer K, Kratz KL. Occurrence of antibiotics in the aquatic environment. Science of the Total Environment 1999:225:109-21.

Huerta-Fontela M, Galceran MT, Martin-Alonso J, Ventura F. Occurrence of psychoactive stimulatory drugs in wastewaters in North-Eastern Spain. Science of the Total Environment 2008;397:31-40.

Hulsbeek JJW, Kruit J, Roeleveld PJ, van Loosdrecht MCM. A practical protocol for dynamic modelling of activated sludge systems. Water Science and Technology 2002;45:127-36.

Johnson AC. Natural variations in flow are critical in determining concentrations of point source contaminants in rivers: An estrogen example. Environmental Science \& Technology 2010;44(20):7865-70.

Joss A, Keller E, Alder AC, Göbel A, McArdell CS, Ternes T, Siegrist H. Removal of pharmaceuticals and fragrances in biological wastewater treatment. Water Research 2005;39(14):3139-52.

Kleywegt S, Pileggi V, Yang P, Hao C, Zhao X, Rocks C, Thach S, Cheung P, Whitehead B. Pharmaceuticals, hormones and bisphenol A in untreated 
source and finished drinking water in Ontario, Canada - Occurrence and treatment efficiency. Science of the Total Environment 2011;409:1481-8.

Kümmerer K. Antibiotics in the aquatic environment - A review - Part I. Chemosphere 2009;75(4):417-34.

Lissemore L, Hao C, Yang P, Sibley PK, Mabury S, Solomon KR. An exposure assessment for selected pharmaceuticals within a watershed in Southern Ontario. Chemosphere 2006;64(5):717-29.

Neu HC. The crisis in antibiotic resistance. Science 1992;257(5073):1064-73.

Noh J, Han D, Yoon J, Kim M, Kim S, Ko I, Kim K, Kim C, Cho S. Circadian rhythms in urinary functions: Possible roles of circadian clocks? International Neurology Journal 2011;15:64-73.

Ort C, Lawrence MG, Reungoat J, Mueller JF. Sampling for PPCPs in wastewater systems: Comparison of different sampling modes and optimization strategies. Environmental Science \& Technology 2010;44(16):6289-96.

Pandi-Permural S, Cardinali D, editors. Melatonin: From Molecules to Therapy. Nova Publisher, New York, USA, 2007.

Plósz BG, Leknes H, Liltved H, Thomas KV. Diurnal variations in the occurrence and the fate of hormones and antibiotics in activated sludge wastewater treatment in Oslo, Norway. Science of the Total Environment 2010;408(8):1915-24. 
Pruden A, Pei R, Storteboom H, Carlson KH. Antibiotic resistance genes as emerging contaminants: Studies in northern Colorado. Environmental Science \& Technology 2006;40(23):7445-50.

Rauch W, Brockmann D, Peters I, Larsen TA, Gujer W. Combining urine separation with waste design: An analysis using a stochastic model for urine production. Water Research 2003;37(3):681-9.

Rimkus GG. Polycyclic musk fragrances in the aquatic environment. Toxicology Letters 1999;111(1-2):37-56.

Salgado R, Marques R, Noronha J, Mexia J, Carvalho G, Oehmen A, Reis M. Assessing the diurnal variability of pharmaceutical and personal care products in a full-scale activated sludge plant. Environmental Pollution 2011;159(10):2359-67.

Santos J, Aparicio I, Callejón M, Alonso E. Occurrence of pharmaceutically active compounds during 1-year period in wastewaters from four wastewater treatment plants in Seville (Spain). Journal of Hazardous Materials 2009;164:1509-16.

Servais P, Passerat J. Antimicrobial resistance of fecal bacteria in waters of the Seine river watershed (France). Science of the Total Environment 2009;408:365-72.

Tamtam F, Mercier F, Bot BL, Eurin J, Dinh QT, Clément M, Chevreuil M. Occurrence and fate of antibiotics in the Seine river in various hydrological conditions. Science of the Total Environment 2008;393:84-95. 
Tchobanoglous G, Burton FL, Stensel HD. Wastewater Engineering: Treatment and Reuse. McGraw-Hill, New York, USA, 2003.

Teerlink J, Hering A, Higgins C, Drewes J. Variability of trace organic chemical concentrations in raw wastewater at three distinct sewershed scales. Water Research 2012;46:3261-71.

Ternes TA, Joss A, editors. Human pharmaceuticals, hormones and fragrances: The challenge of micropollutants in urban water management. IWA Publishing, London UK, 2006.

Verlicchi P, Al Aukidy M, Zambello E. Occurrence of pharmaceutical compounds in urban wastewater: Removal, mass load and environmental risk after a secondary treatment-A review. Science of the Total Environment 2012;429:123-55.

Vernaz N, Sax H, Pittet D, Bonnabry P, Schrenzel J, Harbarth S. Temporal effects of antibiotic use and hand rub consumption on the incidence of MRSA and Clostridium difficile. Journal of Antimicrobial Chemotherapy 2008;62(3):601-7.

Welch P. The use of fast Fourier transform for the estimation of power spectra: A method based on time averaging over short, modified periodograms. IEEE Transactions on Audio and Electroacoustics 1967;15:70-3. 

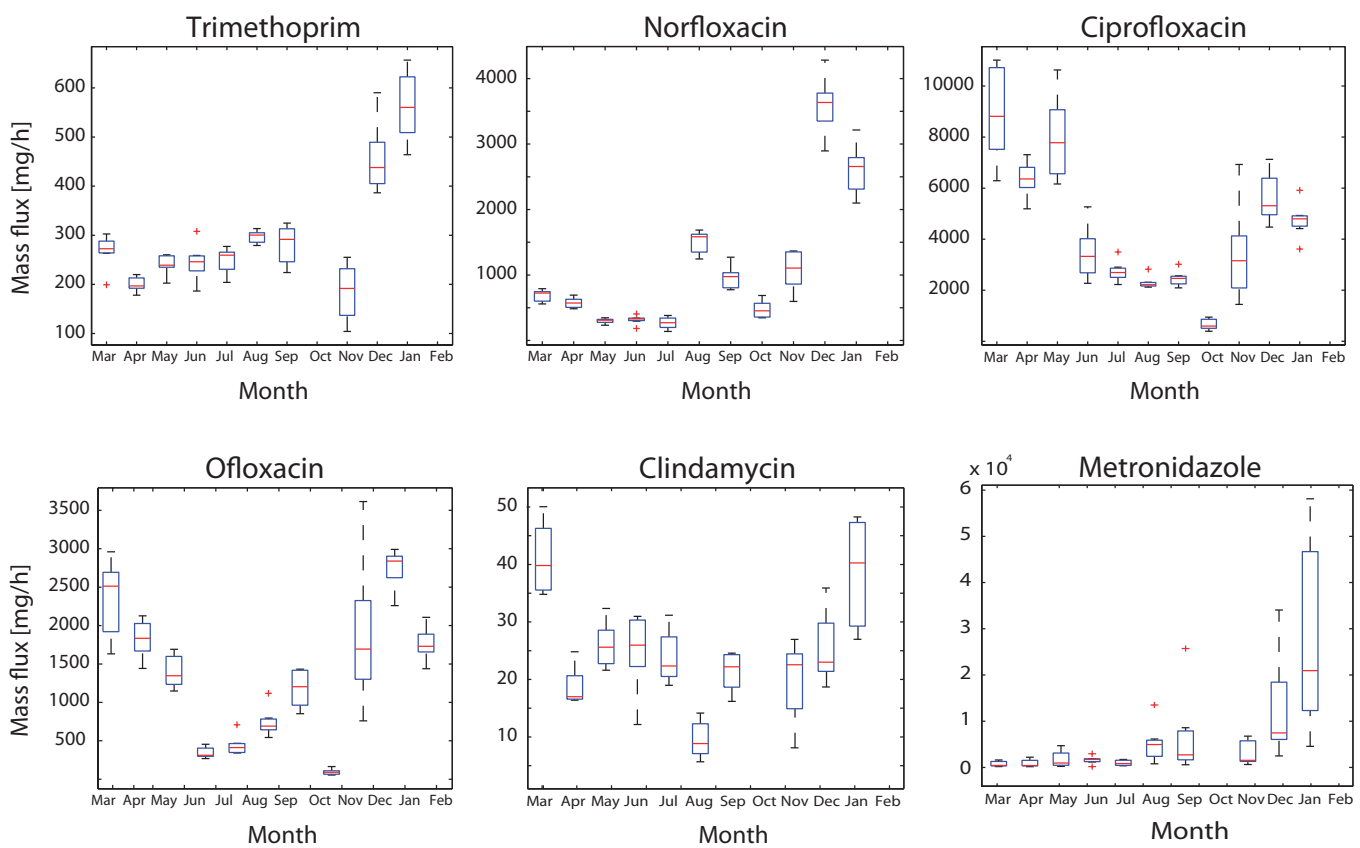

Figure 1: Boxplots of mass fluxes of the six antibiotics investigated (one box per month). Each box was obtained from seven daily samples. Upper and lower box limits correspond to the $75^{\text {th }}$ and $25^{\text {th }}$ percentiles, respectively. Upper and lower whiskers correspond to the last datum being respectively still within $1.5 \mathrm{IQR}$ of the higher and lower quartile. IQR is the interquartile range, i.e., the difference between the upper and lower quartiles. 


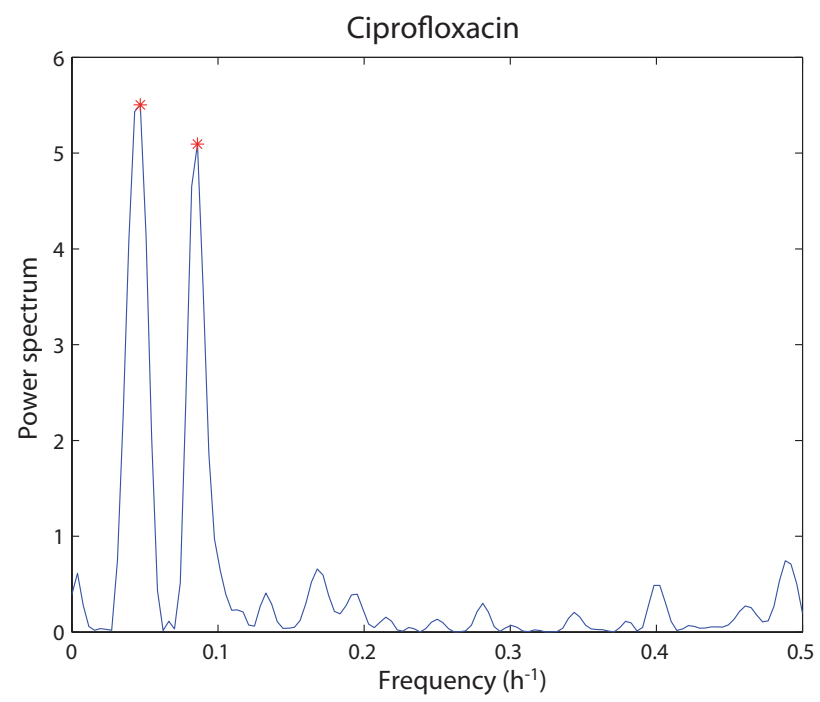

Figure 2: Periodogram of the measured ciprofloxacin hourly mass flux. Peaks in the power spectrum observed at $0.042 \mathrm{~h}^{-1}$ and $0.083 \mathrm{~h}^{-1}$, which correspond to periods of $24 \mathrm{~h}$ and 12 $\mathrm{h}$, respectively. The same periods were observed for the other substances (Supplementary data). 


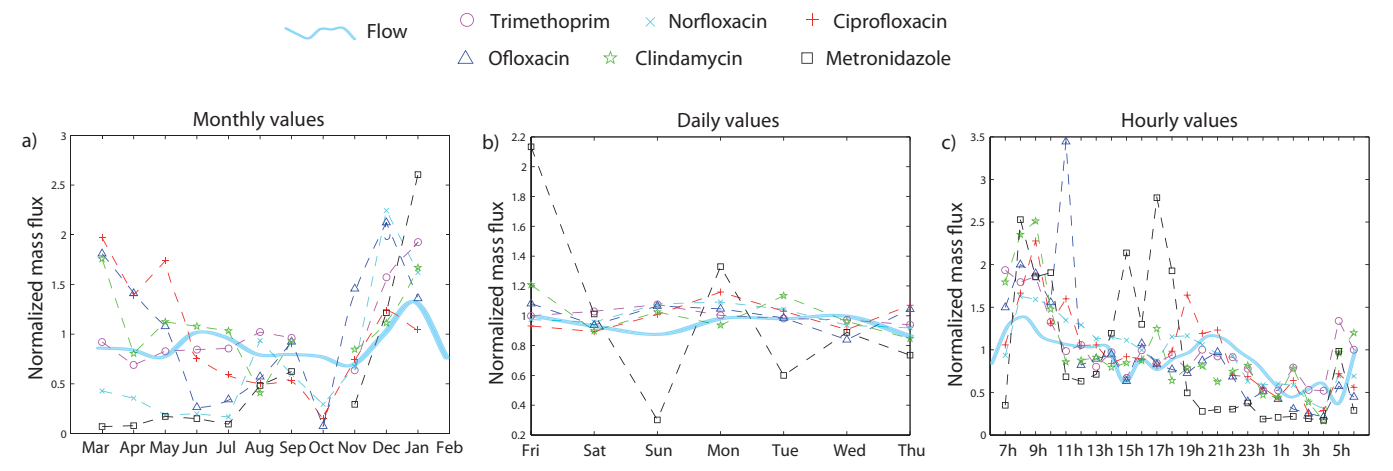

Figure 3: Fluctuations of mass flux at different time scales: month a), day b), and hour c). In a), each symbol corresponds to the average mass flux of the seven daily samples collected in the corresponding month. In b), each symbol corresponds to the average value of the twelve times (one per month) the corresponding day was sampled. In c), each point corresponds to the average of the four times (four 24-h campaigns) the corresponding hour was sampled. Mass flux is normalized to mean mass flux over the considered time scale. For example, in a) the monthly mass flux was normalized by the mean of the monthly mass fluxes measured over the year. Clear variability is observed at the monthly and hourly time scales for all substances. No variability is observed at the daily time scale, except for metronidazole. The corresponding flow — normalized to the mean flow over the considered time scale — is shown on each graph by the blue line. The monthly mean flow includes rainwater peaks in addition to baseflow. Daily and hourly mean flows were selected to include only dry periods, i.e., their fluctuation is not affected by any rain input. 

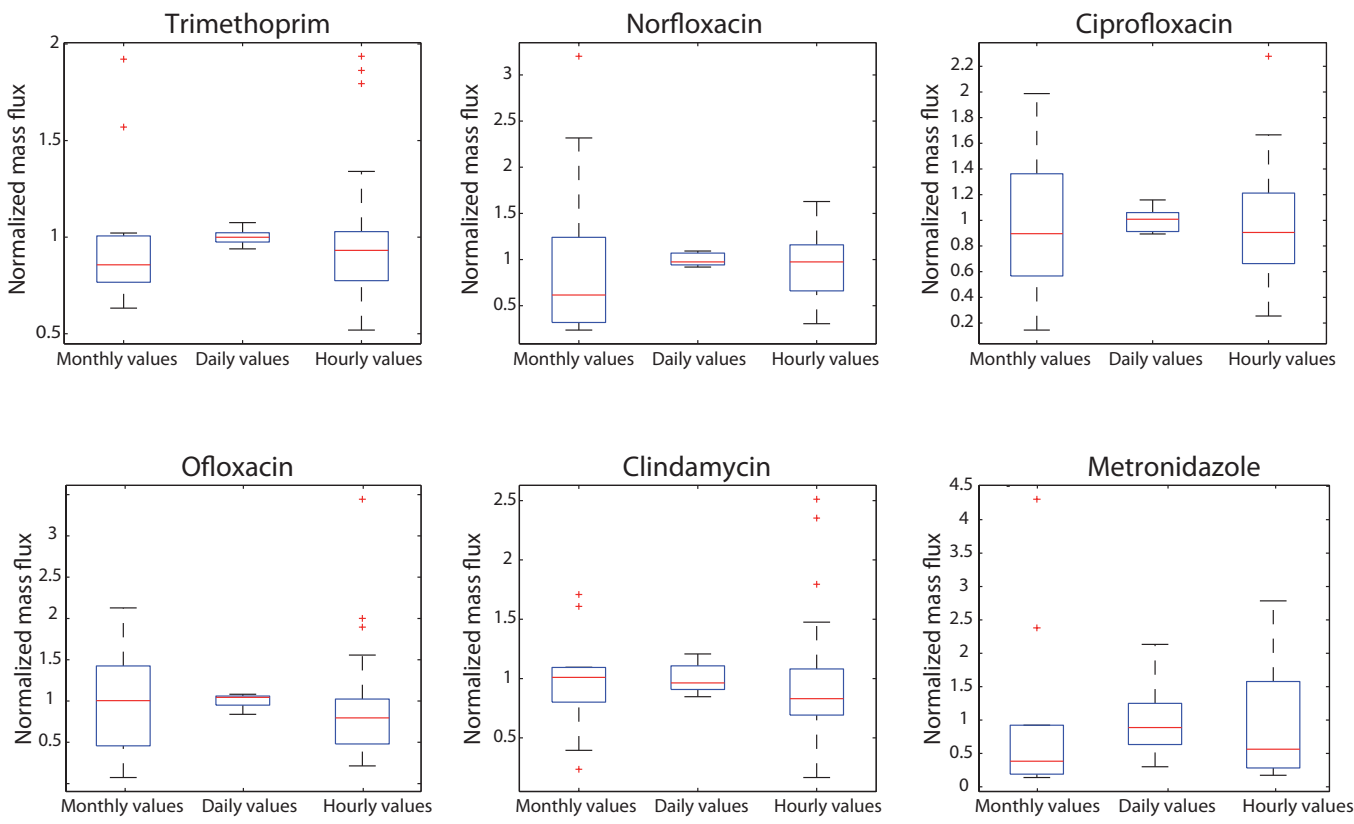

Figure 4: Boxplots illustrating the dispersion of the measured mass fluxes for the three different time scales $(\mathrm{m}, \mathrm{d}, \mathrm{h})$. Similar to Figure 3, the mass flux is normalized by the mean mass flux over the considered time scale. For each substance, the box on the left is obtained from the 12 mean monthly values (the 12 values in Figure 3a), the box in the middle from the seven mean daily values (seven values in Figure $3 \mathrm{~b}$ ), and the box in the right from the 24 mean hourly values (the 24 values in Figure 3c). Boxes were computed following the same rule described in Figure 1. 
Table 1: Summary of studies assessing the temporal dynamics of antibiotics in WTP influent.

\begin{tabular}{|c|c|c|c|}
\hline Study & Antibiotic & $\begin{array}{l}\text { Sampling regime at the } \\
\text { WTP inlet }\end{array}$ & $\begin{array}{l}\text { Sampler } \\
\text { position }\end{array}$ \\
\hline Joss et al. (2005) & $\begin{array}{l}\text { Roxithromycin, } \\
\text { sulfamethoxazole }\end{array}$ & $\begin{array}{l}\text { 8-h composite samples of } \\
\text { primary effluent taken during } \\
\text { one day }\end{array}$ & $\begin{array}{l}\text { After primary } \\
\text { clarifier }\end{array}$ \\
\hline Göbel et al. (2005) & $\begin{array}{l}\text { Sulfadiazine, } \\
\text { sulfathiazole, } \\
\text { sulfapyridine, } \\
\text { sulfamethoxazole, } \\
\text { trimethoprim, } \\
\text { erythromycin, } \\
\text { clarithromycin }\end{array}$ & $\begin{array}{l}\text { Flow-proportional 8-h } \\
\text { composite sample during one } \\
\text { day plus three weekly } \\
\text { campaigns to assess } \\
\text { seasonality (three } \\
\text { flow-proportional composite } \\
\text { samples, one combining } 24 \text {-h } \\
\text { integrated samples from } \\
\text { Saturday and Sunday and two } \\
\text { combining two or three } \\
\text { weekdays) }\end{array}$ & $\begin{array}{l}\text { WTP inlet, } \\
\text { before clarifier }\end{array}$ \\
\hline Plósz et al. (2010) & $\begin{array}{l}\text { Ciprofloxacin, } \\
\text { trimethoprim, } \\
\text { sulfamethoxazole, } \\
\text { tetracycline }\end{array}$ & $\begin{array}{l}\text { Three-day measurement } \\
\text { campaign. 8-h } \\
\text { flow-proportional composite } \\
\text { samples. Sampling frequency } \\
\text { of } 15 \mathrm{~min}\end{array}$ & $\begin{array}{l}\text { After primary } \\
\text { clarifier }\end{array}$ \\
\hline Ort et al. (2010) & $\begin{array}{l}\text { Chloramphenicol, } \\
\text { trimethoprim, } \\
\text { roxithromycin, } \\
\text { lincomycin, } \\
\text { erythromycin, } \\
\text { cephalexin, dapsone, } \\
\text { sulphadiazine }\end{array}$ & $\begin{array}{l}\text { Tested several sampling } \\
\text { strategies and recommended a } \\
\text { 5-min sampling frequency to } \\
\text { characterize intra-day } \\
\text { fluctuations in WTP influent }\end{array}$ & $\begin{array}{l}\text { WTP inlet, } \\
\text { before clarifier }\end{array}$ \\
\hline Gerrity et al. (2011) & $\begin{array}{l}\text { Trimethoprim, } \\
\text { sulfamethoxazole }\end{array}$ & $\begin{array}{l}\text { Two } 12 \text {-h campaigns with a } \\
\text { sampling frequency of } 30 \mathrm{~min}\end{array}$ & $\begin{array}{l}\text { After primary } \\
\text { clarifier }\end{array}$ \\
\hline Salgado et al. (2011) & Ampicillin & $\begin{array}{l}\text { Two 48-h campaigns with a } \\
\text { sampling frequency of } 2 \mathrm{~h}\end{array}$ & $\begin{array}{l}\text { WTP inlet, } \\
\text { before clarifier }\end{array}$ \\
\hline Teerlink et al. (2012) & $\begin{array}{l}\text { Trimethoprim, } \\
\text { sulfamethoxazole }\end{array}$ & $\begin{array}{l}\text { One } 26 \text {-h campaign with a } \\
\text { sampling frequency of } 1 \mathrm{~h}\end{array}$ & $\begin{array}{l}\text { WTP inlet, } \\
\text { before clarifier }\end{array}$ \\
\hline
\end{tabular}


Table 2: Description of the methodology used to obtain the monthly, daily and hourly samples in the field campaign. Samples were all collected at the same location at the Vidy WTP entrance.

\begin{tabular}{|c|c|c|c|}
\hline Type of sample & Sample aggregation & Number of samples & Frequency \\
\hline Monthly samples & $\begin{array}{l}\text { Flow proportional average of } \\
\text { seven consecutive daily samples }\end{array}$ & 12 & One per month \\
\hline Daily samples & $\begin{array}{l}200 \mathrm{ml} \text { samples collected } \\
\text { every hour during a day. } \\
\text { The } 24 \text { samples were mixed flow } \\
\text { proportionally to get the daily average }\end{array}$ & 84 & $\begin{array}{l}7 \mathrm{~d} \text { (1 week) } \\
\text { per month }\end{array}$ \\
\hline Hourly samples & $\begin{array}{l}200 \mathrm{ml} \text { samples collected } \\
\text { every } 15 \mathrm{~min} \text { during an hour. } \\
\text { Each hour, the four } 200 \mathrm{ml} \text { samples } \\
\text { were aggregated to form an hourly sample }\end{array}$ & 96 & $\begin{array}{c}\text { Four } 24 \mathrm{~h} \\
\text { campaigns } \\
\text { (May, September, } \\
\text { November, December) }\end{array}$ \\
\hline
\end{tabular}


Table 3: Precision of the laboratory analysis.

\begin{tabular}{|c|c|c|c|c|c|c|}
\hline & Analyte & $\begin{array}{c}\text { RSD }(\%)^{a} \\
\text { Within one run }\end{array}$ & $\left(\mathrm{R}^{2}\right)^{b}$ & $\mathrm{LOD}^{c}(\mathrm{ng} / \mathrm{L})$ & $\mathrm{LOQ}^{d}(\mathrm{ng} / \mathrm{L})$ & Recovery $(\%)^{e}$ \\
\hline 1 & Trimethoprim & 2 & 0.9993 & 1.3 & 4 & $88 \pm 1$ \\
\hline 2 & Norfloxacin & 8 & 0.9827 & 1.3 & 4 & $118 \pm 43$ \\
\hline 3 & Ciprofloxacin & 1 & 0.9963 & 1.2 & 3.5 & $105 \pm 7$ \\
\hline 4 & Ofloxacin & 7 & 0.9959 & 1.2 & 3.5 & $90 \pm 11$ \\
\hline 5 & Clindamycin & 1 & 0.9961 & 1.1 & 3.3 & $86 \pm 1$ \\
\hline 6 & Metronidazole & 4 & 0.9972 & 1 & 3 & $116 \pm 22$ \\
\hline
\end{tabular}

${ }^{a}$ Relative Standard Deviation: concentrations detected in the samples during one continuous sequence of analysis. Three replicates were carried out

${ }^{b}$ Correlation coefficient with seven concentration levels. Norfloxacin, ofloxacin: $0.2-350$ ng/L; trimethoprim, clindamycin: 0.3 - $630 \mathrm{ng} / \mathrm{L}$ and ciprofloxacin, metronidazole: 0.4 $700 \mathrm{ng} / \mathrm{L}$

${ }^{c}$ Limit of detection calculated as a signal to noise $(\mathrm{S} / \mathrm{N})$ ratio of $3 / 1$

${ }^{d}$ Limit of quantification calculated as a signal to noise $(\mathrm{S} / \mathrm{N})$ ratio of $10 / 1$

${ }^{e}$ Quality control samples (three replicates) prepared in three injection vials for each analyte with known concentrations of 3, 30 and $150 \mathrm{ng} / \mathrm{L}$. Three replicates were carried out 